\title{
Kesiapan Technological, Pedagogical And Content Knowledge (Tpack) Calon Guru Bidang Teknik di Universitas Negeri Malang
}

\author{
Ulum Furqon Arbiyanto ${ }^{1}$, Widiyanti ${ }^{2}$, dan Didik Nurhadi ${ }^{3}$ \\ 1,2,3 Program Studi S1 Pendidikan Teknik Mesin Jurusan Teknik Mesin \\ ${ }^{1,2,3}$ Fakultas Teknik Universitas Negeri Malang \\ 1,2,3 Jalan Semarang No. 5, Malang 65145 \\ Email: Ulumarbi1995@gmail.com
}

\begin{abstract}
Abstrak: Tujuan pendidikan nasional Republik Indonesia adalah mencerdaskan kehidupan bangsa. Tujuan tersebut merupakan suatu penghargaan agar bangsa Indonesia bisa bersaing dengan bangsa lain di kancah internaisional khususnya di era Revolusi Industri Keempat (R.I 4.0) dan era Masyarakat ekonomi Asean (MEA) saat ini. Sudah saatnya pendidikan di Indonesia berbenah agar bangsa bisa bersaing dengan bangsa lain. Pembenahan yang mendasar dalam pendidikan adalah terkait kualitas dan kompetensi guru maupun calon guru Indonesia. Calon guru harus mencermati bagaimana kualitasnya untuk menjadi guru, bagaimana menyadari posisi mereka dalam era revolusi industri saat ini. Hadirnya perkembangan ilmu pengetahuan dan teknologi (IPTEK) bisa dijadikan salah satu cara untuk bisa mewujudkan hal tersebut, seorang guru harus memiliki dan paham betul tentang kemampuan Technological Pedagogical Content Knowledge (TPACK) yang mengidentifikasi bahwa hal tersebut merupakan pengetahuan penting untuk pengembangan keterampilan professional guru dan calon guru.
\end{abstract}

Kata Kunci: Technological Pedagogical Content Knowledge, Calon Guru, Fakultas Teknik UM

Perubahan dunia kini tengah memasuki era revolusi industri 4.0 atau revolusi industri dunia keempat dimana teknologi informasi telah menjadi basis dalam kehidupan manusia. Segala hal menjadi tanpa batas (borderless) dengan penggu-naan daya komputasi dan data yang tidak terbatas (unlimited), karena dipengaruhi oleh perkembangan internet dan teknologi digital yang masif sebagai tulang punggung pergerakan dan konektivitas manusia dan mesin. Era ini juga akan menilai berbagai aktivitas manusia, termasuk di dalamnya bidang ilmu pengetahuan dan teknologi (iptek) di pendidikan tinggi.

Revolusi Industri 4.0 ber-basis teknologi menekankan bahwa Perguruan Tinggi harus merespon RI 4.0 ini perlu mengaplikasikan tek-nologi dalam pembelajaran. Kemenristekdikti mengatakan saat Rakernas 2018 di Universitas Suma-tra Utara (USU), bahwa "Kebijakan strategis perlu dirumuskan dalam ber-bagai aspek mulai dari kelembagaan, bidang studi, kurikulum, sumber daya, serta pengembangan cyber university, risbang hingga inovasi. Diharapkan dalam Rakernas ini dapat dihasilkan rekomendasi pengemba-ngan iptek dikti dalam menghadapi revolusi industri 4.0".

Oleh karena itu, sumber daya manusia perguruan tinggi yaitu dosen dan mahasiswa calon guru perlu memiliki kompetensi tentang penerapan teknologi dalam pembe-lajaran baik dikelas maupun dan diluar kelas. Teknologi yang dapat diterapkan dalam pembelajaran misal-nya animasi, game, pengggunaan social media seperti facebook, twitter, whatsapp, internet dan lain-lain.

Jurnal penelitian dari Mishra dan Koehler (2006) dengan judul Technological Pedagogical Content Knowledge: $A$ framework for Teacher Knowledge, sampai saat ini telah menjadi acuan oleh banyak peneliti dan praktisi pendidikan dalam upaya mengembangkan beberapa model pembelajaran. Istilah yang kemudian dikenal dengan Technological, Pedagogical, Content Knowledge (TPACK) adalah sebuah framework (kerangka kerja) dalam merancang pembelajaran baru dengan menggabungkan tiga aspek utama yaitu teknologi, pedagogik dan penge-tahuan konten.

Kemajuan teknologi infor-masi yang sedemikian pesatnya adalah sebuah keniscayaan bahwa guru harus menguasai teknologi untuk kemudian digunakan sebagai media pendukung dalam kegiatan pembelajaran. Menurut Hidayat (2015) menyatakan bahwa guru yang profesional adalah guru yang mampu menguasai materi dan mampu memanfaatkan sumber yang ada termasuk dalam hal ini guru memanfaatkan teknologi informasi dan komunikasi dalam pembelajara. Beberapa contoh penerapan teknologi dalam pembelajaran adalah seperti gagasan yang ditawarkan oleh North American Council for Online Lear-ning (NACOL) yaitu model pem-belajaran campuran (blended lear-ning). Pada model ini pembelajaran tidak terfokus pada kegiatan tatap muka dikelas (face to face), tetapi menggunakan juga teknologi berbasis web (online learning) untuk mendukung kegiatan pembelajaran yang telah dilakukan dikelas. Blended learning akhirnya menjadi model pembelajaran yang cukup efek-tif, suasana yang jenuh belajar di kelas dapat diatasi dengan kegiatan belajar yang menyenangkan dan inte-raktif secara online. Penggunaan tek-nologi yang berbasis web ini mung-kin terbilang cukup mahal, karena membu-tuhkan perangkat 
elektronik seperti komputer, laptop ataupun smart phone. Namun teknologi yang dimaksudkan dapat juga berupa alat-alat peraga (tools) hasil pengem-bangan kreativitas para guru, dan tetap mengacu pada kebaruan tek-nologi.

Selain penggunaan teknolo-gi sebagai media belajar, dalam framework TPACK, pedagogik ada-lah aspek penting yang perlu diperhatikan dalam kegiatan pem-belajaran. Pedagogi bukan saja bagaimana mengembangkan seni-seni dalam mengajar, atau mendesain kelengkapan instrumen-instrumen proses dan penilaian dalam pem-belajaran, namun dituntut juga memahami siswa secara psikologis dan biologis. Dalam pemikiran secara pedagogik ini akhirnya ada sebuah penekanan, bahwa guru yang berhasil bukanlah guru yang hanya bisa menjadikan siswanya pintar seperti dirinya, namun lebih dari itu yakni berhasil membantu siswa dalam menemukan dirinya sendiri. Minat, bakat serta karakter peserta didik akhirnya harus dipahami oleh seorang guru. Irina dan Liliana (2011) menjelaskan bahwa kompetensi pe-dagogik adalah kemampuan indi-vidual guru untuk mengkoor-dinasikan dan mengkombinasikan antara sumber-sumber yang tampak (seperti materi pelajaran dalam bentuk buku, makalah, kasus-kasus dan teknologi seperti software dan hardware), dengan sumber-sumber yang tidak tampak (seperti pe-ngetahuan, keterampilan dan penga-laman), dalam rangka mencapai efisiensi dan efektivitas dari sebuah proses pendidikan dan pembelajaran.

Pengetahuan konten (con-tent knowledge) pada kerangka kerja TPACK, adalah elemen dasar yang harus dimiliki oleh seorang guru sesuai disiplin keilmu-annya. Anwar dalam Siregar (2010) menyatakan bahwa Pengetahuan Konten merupakan pengetahuan sains yang semestinya dikuasai oleh pengajar mencakup fakta, konsep, prinsip, hukum, dan teori. Rata-rata nilai UKG yang cukup rendah di Jawa Timur atau dibeberapa daerah lainnya, adalah potret yang cukup memprihatinkan dalam dunia pen-didikan. Masalah ini memang perlu "sentuhan tangan" pemerintah untuk lebih serius lagi dalam membuat regulasi yang lebih ketat terkait guru profesional. Pada kenyataannya dila-pangan banyak diantara guru pro-fesional (bersertifikasi) yang justru salah "masuk ruang” (mismatch), sebagai contoh guru Kimia dari lulusan S1 Pertanian/Kehutanan, guru Bahasa Indonesia dari lulusan S1 Biologi dan sebagainya. Untuk me-ningkatkan content knowledge, latar belakang pendidikan sangatlah pen-ting, selain itu guru tidaklah cukup hanya mengandalkan text book semata, namun perlu didukung de-ngan mengupdate informasi terkini bidang keilmuan terkait yang di publikasikan oleh lembaga lemba-ga jurnal penelitian terpercaya

TPACK akhirnya menjadi sebuah kerangka kerja untuk peneliti dan praktisi pendidikan, dalam upaya untuk mengemas dan mengem-bangkan model pembelajaran agar tercapai tujuan pembelajaran melalui proses yang lebih baik. Pengetahuan teknologi, pedagogik, dan konten pengetahuan, seyogianya terkumpul dalam diri seorang guru, namun sepertinya ada yang kurang lengkap dari gagasan besar Mishra dan Koehler (2008) tentang TPACK, yaitu kepribadian yang santun (good personality) yang harus dimiliki seorang guru. Kenakalan peserta didik, pergaulan bebas, hingga kasus kriminal yang dilakukan oleh peserta didik, sudah mirip deret hitung yang setiap tahunnya mengalami kemajuan pesat. Oleh karenanya, diperlukan kesadaran kolektif guru dalam men-cermati masalah serius ini. Dampak kemajuan teknologi informasi, penga-ruh lingkungan tempat tinggal atau latar belakang keluarga, diyakini sebagai yang paling bertanggung jawab terhadap merosotnya moral dikalangan pelajar.

Perkembangan ilmu penge-tahuan dan teknologi informasi atau IPTEK menjadi sebuah tantangan yang harus dihadapi oleh calon guru dengan mengedepankan kemampuan-nya. Sesuai dengan Undang-undang Republik Indonesia Nomor 14 tahun 2005 tentang guru dan dosen dalam meningkatkan daya saing apa bila ada lulusan S1 Nonkependidikan yang menjadi guru ataupun dosen. Hal ini tentu menjadi tantangan bagi lulusan S1 kependidikan utamanya di Fakultas Teknik untuk meningkatkan kualitas dan kemampuanya untuk bersaing dengan yang lain di Era MEA saat ini.

\section{METODE PENELITIAN}

Penelitian ini menggunakan metode penelitian secara deskriptif dengan pendekatan kuantitatif karena teknik pengumpulan data yang digunakan menggunakan angket, wawancara, observasi. Deskriptif kuantitatif merupa-kan jenis pendekatan pada suatu penelitian yang mendeskripsikan ten-tang populasi atau sampel yang di teliti secara objektif dengan menggu-nakan angka, mulai dari pengumpulan data, penafsirkan terhadap angka ter-sebut, sampai pada penampilan hasil-nya. Penelitian deskriptif biasanya hanya menggunakan satu variabel saja sehingga cenderung tidak di maksudkan untuk mengungkap hubu-ngan antar variabel atau menguji hipotesis.

Pemilihan metode dan pendekatan didasarkan pada tujuan untuk melihat Kesiapan Techno-logical, Pedagogical And Content Knowledge (TPACK) Calon Guru Bi-dang Teknik di Universitas Negeri Malang. Proses pengambilan sampel dilakukan dengan teknik proportional random sampling sehingga dikelom-pokkan ke dalam beberapa strata, pada penelitian ini jumlah sampel akan dikelompokkan ke dalam 7 strata sesuai dengan jumlah prodi. Penggunaan teknik proporsional sampling dikarenakan be-berapa alasan yaitu waktu yang terbatas, tidak memungkinkan jika harus me-ngambil sampel sebanyak itu dan res-ponden tersebut merupakan mahasiswa semester akhir.

Untuk mengambil keputusan tingkat interpretasi data dengan menggunakan pendekatan kategori jenjang yang memanfaatkan skor total sebgai acuannya. Rumus pengkatego-riannya adalah sebagai berikut: 
Tabel 1 Kategori Interpretasi

\begin{tabular}{ll}
\hline Interval & Kategori \\
\hline $\mathrm{M}+1,5 \mathrm{SD}<\mathrm{X}$ & Sangat Baik \\
$\mathrm{M}+0,5 \mathrm{SD}<\mathrm{X} \leq \mathrm{M}+1,5 \mathrm{SD}$ & Baik \\
$\mathrm{M}-0,5 \mathrm{SD}<\mathrm{X} \leq \mathrm{M}+0,5 \mathrm{SD}$ & Cukup \\
$\mathrm{M}-1,5 \mathrm{SD}<\mathrm{X} \leq \mathrm{M}-0,5 \mathrm{SD}$ & Kurang Baik \\
$\mathrm{X} \leq \mathrm{M}-1,5 \mathrm{SD}$ & Tidak baik \\
\hline
\end{tabular}

(Azwar, 2013)

\section{HASIL PENELITIAN}

Deskripsi data hasil penelitian ini dimaksudkan untuk menggambar-kan data mengenai tingkat kesiapan technological pedagogical content knowledge (TPACK) calon guru bi-dang teknik di Universitas Negeri Malang..

\section{Kesiapan Technological Knowledge (TK) calon guru bidang teknik di Universitas Negeri Malang}

Technological Knowledge adalah pengetahuan tentang teknologi dan memiliki pengetahuan yang berguna untuk menggunakan dan mempelajari teknologi yang tersedia (Jordan, 2011)

Hasil analisi deskriptif me-nunjukkan bahwa tingkat kesiapan TK calon guru bidang teknik di-peroleh skor terendah (minimum) 6, skor maksimal (maximal) 24, rerata (mean) 15.79, nilai tengah (median) 16.50, nilai yang sering muncul (mode) 17, dan standat deviasi (SD) 3,806.

Sementara, hasil analisis kesiapan Technological Knowledge calon guru bidang teknik di UM menunjukkan persentase tertinggi yaitu pada kategori baik (42\%).

Tabel 2 Tabel Frekuensi Kesiapan Technological Knowledge

\begin{tabular}{lll}
\hline Kategori & Frekuensi & Persentase \\
\hline Sangat Baik & 15 & $7 \%$ \\
Baik & 80 & $42 \%$ \\
Cukup & 53 & $28 \%$ \\
Kurang Baik & 31 & $17 \%$ \\
Tidak baik & 11 & $6 \%$ \\
\hline
\end{tabular}

Dengan mempertimbangkan nilai mean 15.66 maka dapat ditarik kesimpulan bahwa tingkat kesiapan Technological Knowledge calon guru termasuk dalam kategori baik.

\section{Kesiapan Pedagogical Knowledge (PK) calon guru bidang teknik di Universitas Negeri Malang}

Pedagogical Knowledge merupakan pengetahuan guru tentang berbagai pelaksanaan, strategi dan metode untuk mendukung pem-belajaran peserta didik (Koehler, 2014). Hasil analisis deskriptif menunjukkan bahwa tingkat kesiapan PK calon guru bidang teknik diperoleh skor terendah (minimum) 8, skor maksimal (maximal) 32, rerata (mean) 20.04, nilai tengah (median) 21, nilai yang sering muncul (mode) 16, dan standat deviasi (SD) 6,047.

Sementara, hasil analisis kesiapan Pedagogical Knowledge calon guru bidang teknik di UM menunjukkan persentase tertinggi yaitu pada kategori cukup (34\%).

Tabel 3. Tabel Frekuensi Kesiapan Pedagogical Knowledge (PK)

\begin{tabular}{lll}
\hline Kategori & Frekuensi & Persentase \\
\hline Sangat Baik & 24 & $13 \%$ \\
Baik & 51 & $26 \%$ \\
Cukup & 65 & $34 \%$ \\
Kurang Baik & 39 & $21 \%$ \\
Tidak baik & 11 & $6 \%$ \\
\hline & $\mathbf{1 9 0}$ & $\mathbf{1 0 0 \%}$
\end{tabular}


Dengan mempertimbangkan nilai mean yang didapat yaitu sebesar 20.49 dan jawaban responden yang sebagian besar termasuk kategori baik, maka dapat ditarik kesimpulan bahwa tingkat kesiapan pedagogical knowledge calon guru termasuk dalam kategori cukup.

\section{Kesiapan Content Knowledge (CK) Calon Guru Bidang Teknik di Universitas Negeri Malang}

Content Knowledge merupa-kan pengetahuan tentang konsep, teori, gagasan, kerangka kerja, penge-tahuan tentang pembuktian, serta praktik-praktik dan pendekatan untuk mengembangkan pengetahuan terse-but (Shulman, 1986).

Hasil analisi deskriptif menunjukkan bahwa tingkat kesiapan content knowledge calon guru bidang teknik diperoleh skor terendah (minimum) 5, skor maksimal (maximal) 20, rerata (mean) 13.31, nilai tengah (median) 14, nilai yang sering muncul (mode) 15, dan standat deviasi (SD) 3.286.

Tabel 4. Tabel Frekuensi Kesiapan Content Knowledge (CK)

\begin{tabular}{lll}
\hline Kategori & Frekuensi & Persentase \\
\hline Sangat Baik & 11 & $6 \%$ \\
Baik & 90 & $46 \%$ \\
Cukup & 50 & $25 \%$ \\
Kurang Baik & 28 & $17 \%$ \\
Tidak baik & 11 & $6 \%$ \\
\hline
\end{tabular}

Dengan mempertimbangkan nilai mean yang didapat yaitu sebesar 13,31 dan jawaban responden yang sebagian besar termasuk kategori baik, maka dapat ditarik kesimpulan bahwa tingkat kesiapan Content Knowledge calon guru termasuk dalam kategori baik.

\section{Kesiapan Technological Content Knowledge (TCK) Calon Guru Bidang Teknik di Universitas Negeri Malang}

Technological Content Know-ledge merupakan pengetahuan ten-tang timbal-balik antara teknologi dan konten (Koehler, 2014).

Hasil analisi deskriptif menunjukkan bahwa tingkat kesiapan TCK calon guru bidang teknik diperoleh skor terendah (minimum) 7, skor maksimal (maximal) 28, rerata (mean) 19.90, nilai tengah (median) 22, nilai yang sering muncul (mode) 24, dan standat deviasi (SD) 4.461 .

Kemudian hasil analisis kesiapan TCK calon guru bidang teknik di UM menunjukkan persentase tertinggi yaitu pada kategori Sangat baik (43\%).

Tabel 5. Tabel Frekuensi Kesiapan Technological Content Knowledge (TCK)

\begin{tabular}{lll}
\hline Kategori & Frekuensi & Persentase \\
\hline Sangat Baik & 82 & $43 \%$ \\
Baik & 55 & $29 \%$ \\
Cukup & 25 & $13 \%$ \\
Kurang Baik & 23 & $12 \%$ \\
Tidak baik & 5 & $3 \%$ \\
\hline
\end{tabular}

Dengan mempertimbangkan nilai mean yang didapat yaitu sebesar 19,90 dan jawaban responden yang sebagian besar termasuk kategori baik, maka dapat ditarik kesimpulan bahwa tingkat kesiapan Techno-logical Content Knowledge calon guru termasuk dalam kategori baik.

\section{Kesiapan Pedagogical Content Knowledge (PCK) Calon Guru Bidang Teknik di Universitas Negeri Malang}

Pedagogical Content Know-ledge merupakan pengetahuan peda-gogik yang berlaku untuk pengajaran konten yang spesifik. Pengetahuan ini termasuk untuk mengetahui apa pendekatan pengajaran yang sesuai dengan konten dan juga pengetahuan bagaimana elemen konten bisa diatur untuk pengajaran yang lebih baik (Mishra dan Koehler, 2006).

Menunjukkan hasil dari tiap item pertanyaan yang diisi oleh responden yang diuraikan berda-sarkan persentase dari tiap itemnya, menyatakan bahwa kesiapan Peda-gogical Content Knowledge calon guru bidang teknik di UM dalam kategori baik. Pemahaman mahasiswa calon guru tentang Pedagogical Content Knowledge terbilang baik dari segi melakukan evaluasi hasil belajar siswa saat KPL maupun microteaching dan mampu melak-sanakan pembelajaran sesuai ranca-ngan pembelajaran. 
Hasil analisi deskriptif menunjukkan bahwa tingkat kesiapan PCK calon guru bidang teknik diperoleh skor terendah (minimum) 6, skor maksimal (maximal) 24, rerata (mean) 17.05, nilai tengah (median) 17, nilai yang sering muncul (mode) 16, dan standat deviasi (SD) 3,521.

Sementara hasil analisis kesiapan $P C K$ calon guru bidang teknik di UM menunjukkan persentase tertinggi yaitu pada kategori baik (43\%).

Tabel 6. Tabel Frekuensi Kesiapan Pedagogical Content Knowledge (PCK)

\begin{tabular}{lll}
\hline \multicolumn{1}{c}{ Kategori } & Frekuensi & Persentase \\
\hline Sangat Baik & 27 & $13 \%$ \\
Baik & 84 & $43 \%$ \\
Cukup & 60 & $35 \%$ \\
Kurang Baik & 12 & $6 \%$ \\
Tidak baik & 7 & $3 \%$ \\
\hline
\end{tabular}

Dengan mempertimbangkan nilai mean yang didapat yaitu sebesar 17,05 dan jawaban responden yang sebagian besar termasuk kategori baik, maka dapat ditarik kesimpulan bahwa tingkat kesiapan Pedagogical Content Knowledge calon guru termasuk dalam kategori baik.

\section{Kesiapan Technological Pedagogical Knowledge (TPK) Calon Guru Bidang Teknik di Universitas Negeri Malang}

Technological Pedagogical Knowledge merupakan pengetahuan tentang bagaimana beragam teknologi dapat digunakan dalam pengajaran dan pengunaan teknologi. Menunjuk-kan hasil dari tiap item pertanyaan yang diisi oleh responden yang diuraikan berdasarkan persentase dari tiap itemnya, menyatakan bahwa kesiapan calon guru bidang teknik di UM dalam kategori $T P K$ sudah baik. Pemahaman mahasiswa calon guru tentang $T P K$ terbilang baik dari segi pengetahuan terkait pemanfaatan teknologi pada setiap pembelajaran, dapat menyesuaikan penggunaan teknologi untuk kegiatan pembelaja-ran yang berbeda dan juga dapat menggunakan teknologi informasi dan komunikasi (TIK) untuk ber-diskusi dengan siswa.

Hasil analisi deskriptif menunjukkan bahwa tingkat kesiapan TPK calon guru bidang teknik diperoleh skor terendah (minimum) 8, skor maksimal (maximal) 32, rerata (mean) 21.22, nilai tengah (median) 22, nilai yang sering muncul (mode) 21, dan standat deviasi (SD) 5,557.

Sementara hasil analisis kesiapan $T P K$ calon guru bidang teknik di UM menunjukkan persentase tertinggi yaitu pada kategori baik (48\%).

Tabel 7. Tabel Frekuensi Kesiapan Technological Pedagogical Knowledge (TPK)

\begin{tabular}{lll}
\hline \multicolumn{1}{c}{ Kategori } & Frekuensi & Persentase \\
\hline Sangat Baik & 23 & $12 \%$ \\
Baik & 74 & $40 \%$ \\
Cukup & 50 & $26 \%$ \\
Kurang Baik & 33 & $17 \%$ \\
Tidak baik & 10 & $5 \%$ \\
\hline & $\mathbf{1 9 0}$ & $\mathbf{1 0 0 \%}$ \\
\hline
\end{tabular}

Menunjukkan bahwa tingkat kesiapan Technological Pedagogical Knowledge calon guru bidang teknik di UM berada dikategori tidak baik 0\% (0 orang), Kurang Baik 7\% (10 orang), Cukup 25\% (36 orang), Baik 48\% (71 orang), dan Sangat baik $20 \%$ (29 orang). Dengan mempertimbang-kan nilai mean yang didapat yaitu sebesar 19,92 dan jawaban responden yang sebagian besar termasuk kategori baik, maka dapat ditarik kesimpulan bahwa tingkat kesiapan Technological Pedagogical Knowled-ge calon guru termasuk dalam kate-gori baik.

\section{Kesiapan Technological Pedagogical Knowledge (TPK) calon guru bidang teknik di Universitas Negeri Malang}

$T P K$ merupakan pengetahuan tentang bagaimana beragam teknologi dapat digunakan dalam pengajaran dan pengunaan teknologi tersebut mampu mengubah cara guru mengajar.

Menunjukkan hasil dari tiap item pertanyaan yang diisi oleh responden yang diuraikan berda-sarkan persentase dari tiap itemnya, menyatakan bahwa kesiapan calon guru bidang teknik di UM dalam kategori TPK sudah baik. Pemahaman mahasiswa calon guru tentang $T P K$ terbilang baik dari segi penge-tahuan terkait pemanfaatan teknologi pada setiap pembelajaran, dapat menyesu-aikan penggunaan teknologi untuk kegiatan pembelajaran yang berbeda dan juga dapat menggunakan teknologi informasi dan komunikasi (TIK) untuk berdiskusi dengan siswa. 
Hasil analisi deskriptif menunjukkan bahwa tingkat kesiapan TPK calon guru bidang teknik diperoleh skor terendah (minimum) 6, skor maksimal (maximal) 24, rerata (mean) 14.86, nilai tengah (median) 15.00, nilai yang sering muncul (mode) 16, dan standat deviasi (SD) 4,006.

Sementara hasil analisis kesiapan $T P K$ calon guru bidang teknik di UM menunjukkan persentase tertinggi yaitu pada kategori baik (48\%).

Tabel 8. Tabel Frekuensi Kesiapan Technological Pedagogical Knowledge (TPK)

\begin{tabular}{lll}
\hline Kategori & Frekuensi & Persentase \\
\hline Sangat Baik & 17 & $9 \%$ \\
Baik & 31 & $16 \%$ \\
Cukup & 94 & $49 \%$ \\
Kurang Baik & 32 & $18 \%$ \\
Tidak baik & 16 & $8 \%$ \\
\hline
\end{tabular}

Menunjukkan bahwa tingkat kesiapan TPK calon guru bidang teknik di UM berada dikategori Tidak baik 5\% (10 orang), Kurang Baik 17\% (33 orang), Cukup 26\% (50 orang), Baik 40\% (74 orang), dan Sangat baik 12\% (23 orang). Dengan mempertimbangkan nilai mean yang didapat yaitu sebesar 21,22 dan jawaban responden yang sebagian besar termasuk kategori baik, maka dapat ditarik kesimpulan bahwa tingkat kesiapan TPK calon guru masuk dalam kategori baik.

\section{Kesiapan Technological Pedagogical and Content Knowledge (TPACK) calon guru bidang teknik di Universitas Negeri Malang}

Technological pedagogical and content knowledge merupakan pengetahuan yang dibutuhkan oleh guru untuk mengitegrasikan teknologi ke dalam pengajaran meteri tersebut, menjadi suatu paket yang utuh. Guru harus memiliki pemehaman yang intuitif terhadap interaksi kompleks antara 3 komponen dasar pengeta-huan, yaitu PK, CK dan TK, dengan cara mengajarkan materi tertentu me-nggunakan metode pedagogik dan teknologi yang sesuai (Schmidt et al., 2009).

Menunjukkan hasil dari tiap item pertanyaan yang diisi oleh responden yang diuraikan berdasar-kan persentase dari tiap itemnya, menyatakan bahwa kesiapan calon guru bidang teknik di UM dalam kategori Technological pedagogical and content knowledge baik. Pema-haman mahasiswa calon guru tentang Technological pedagogical and content knowledge terbilang baik dari segi menggunakan strategi yang menggabungkan isi materi, teknologi dan pendekatan pengajaran dalam setiap pembelajaran di kelas dan pengetahuan mengolah pembelajaran dengan pengetahuan materi dikaitkan dengan pengaplikasian teknologi da-lam pembelajaran.

Hasil analisi deskriptif menunjukkan bahwa tingkat kesiapan TPACK calon guru bidang teknik diperoleh skor terendah (minimum) 6, skor maksimal (maximal) 24, rerata (mean) 14.86, nilai tengah (median) 15.00, nilai yang sering muncul (mode) 16, dan standat deviasi (SD) 4,006. Sementara, hasil analisis kesiapan Technological pedagogical and content knowledge calon guru bidang teknik di UM menunjukkan persentase tertinggi yaitu pada kategori baik (49\%).

Tabel 9. Tabel Frekuensi Kesiapan Technological Pedagogical and Content Knowledge (TPACK)

\begin{tabular}{lll}
\hline Kategori & Frekuensi & Persentase \\
\hline Sangat Baik & 17 & $9 \%$ \\
Baik & 31 & $16 \%$ \\
Cukup & 94 & $49 \%$ \\
Kurang Baik & 32 & $18 \%$ \\
Tidak baik & 16 & $8 \%$ \\
\hline & $\mathbf{1 9 0}$ & $\mathbf{1 0 0 \%}$
\end{tabular}

Menunjukkan bahwa tingkat kesiapan TPCK calon guru bidang teknik di UM berada dikategori Tidak baik $8 \%$ (36 orang), Kurang Baik 18\% (32 orang), Cukup 49\% (94 orang), Baik 16\% (31 orang), dan Sangat baik 9\% (17 orang). Dengan mempertimbangkan nilai mean yang didapat yaitu sebesar 14,86 dan jawaban responden masuk kategori cukup, maka dapat ditarik kesimpulan bahwa tingkat kesiapan TPCK calon guru termasuk dalam kategori cukup. 


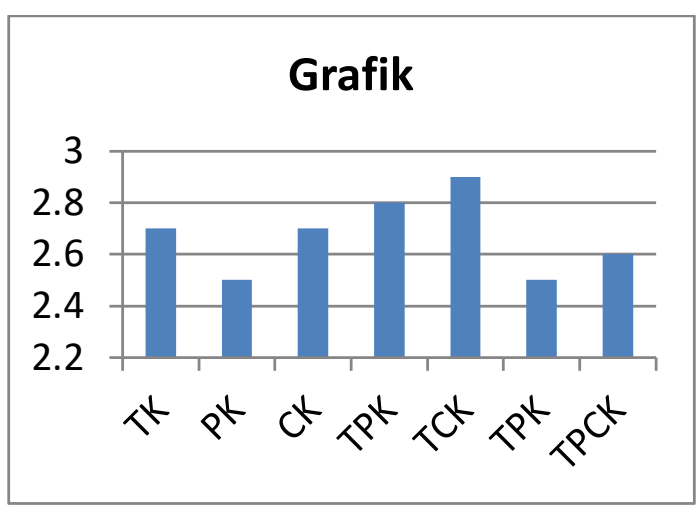

Gambar. Skor rerata kesiapa TPCK calon guru bidang teknik di UM

Dari berbagai paparan ter-sebut, dapat ditarik kesimpulan bah-wa kesiapan TPACK calon guru di fakultas teknik bidang pendidikan sudah baik namun perlu ditingkatkan, terutama dalam segi pengetahuan pedagogik. Mahasiswa calon guru harus tahu bahwa menjadi guru bukan hanya paham teknologi dan konten materi yang akan diajarkannya tetapi juga mengerti cara mengajar, bagai-man menilai kelas yang berbeda, bagaiman mengkondisikan peserta didik agar menjadi siswa yang baik.

\section{SIMPULAN DAN SARAN}

Pertama, kesiapan technologi-cal knowledge (TK) dalam kategori baik dengan nilai mean 15,66. Dengan hasil tersebut, artinya sudah bagus namun tetap ditingkatkan lagi, misalnya pengetahuan teknologi tentang perangkat lunak, tidak hanya bisa Microsoft word atau excel saja tapi juga harus menguasai perangkat lunak lain, misal coreldraw, macro-media flash, paint dan lain-lain.

Kedua, kesiapan dari segi pedagogical knowledge dalam kategori cukup, yaitu dengan nilai mean 20.04, artinya perlu banyak ditingkatkan lagi. Dari segi cara mengajar, bagaimana mengkondisi-kan kelas, bisa mengerti karakterisik peserta didik, mampu memotivasi, mahasiswa calon guru perlu mengembangkannya lagi.

Ketiga, dari kesiapan content knowledge calon guru dalam kate-gori baik, dengan nilai mean 13.18, namun perlu dikembangkan lagi. Pengetahuan materi yang dimiliki perlu diperbanyak lagi, penguasaan materi sangatlah penting, disiplin ilmu serta harus selalu belajar dan mendalami tentang pembelajaran atau pengetahuan baru tentang ma-teri sesuai bidangnya.

Keempat, kesiapan dari segi technological content knowledge calon guru dalam kategori baik, yaitu dengan nilai mean 19,59. Dengan hasil tersebut, tidak ada suatu perma-salah yang terjadi, mungkin perlu ditingkatkan lagi. Sebagai contoh dalam segi pemanfaatan teknologi untuk menyampaikan materi yang hanaya menggunakan powerpoint saja, mungkin bisa menggunakan aplikasi teknologi yang lainya, seperti autoplay atau adobe flash player.

Kelima, kesiapan pedagogical content knowledge calon guru bidang teknik sudah baik, yaitu dengan nilai mean 17.12. Dengan hasil tersebut, masih terdapt permasalahan yang harus dikembangkan lagi. Indikator pada evaluasi belajar misalnya, mahasiswa calon guru memiliki pengetahuan yang minim terkait kemampuan setiap peserta didik sehingga membuat kesulitan dalam melakukan evaluasi belajar, namun dari segi pelaksanaan stategi pembelajaran sudah bagus, sudah mencantumkan lengkap di RPP tinggal mempraktikkannya saja.

Keenam, kesiapan technolog-ical pedagogical knowledge calon guru bidang teknik dalam kategori baik, yaitu dengan nilai mean 19,92. Dengan hasil tersebut, tidak ada masalah yang terjadi, mahasiswa sudah baik dalam memanfaatkan teknologi untuk pembelajaran peda-gogik, misal memanfaatkan jaringna internet sekolah untuk proses pembelajaran e-learning dikelas dan menggunakan media sosial untuk berkomunikasi tugas dengan siswa.

Ketujuh, kesiapan technologi-cal pedagogical content knowledge calon guru bidang teknik dalam kategori baik, yaitu dengan nilai mean 15,15. Dengan hasil tersebut, bahwa kemampuan TPACK calon guru harus dikembangkan lagi perlu diperbaiki lagi jika ingin menjadi guru yang sukses. Dari segi indikator menggunakan strategi yang menghu-bungkan materi, teknologi dan pendekatan, yaitu bagaimana maha-siswa calon guru mampu menen-tukan metode pembelajaran apa yang sesuai dengan kondiis kelas yang diajarnya, bisa memantau sejauh mana kemandirian peserta didik serta sering-sering memberi materi, tugas maupun tes pembelajaran dan juga mampu menentukan pelajaran, mampu menyesuaikan pembelajaran, jangan terpaku pada media power-point, gunakan pembelajaran yang lebih menyenangkan lainya agar bisa memotivasi siswa untuk belajar.

Melihat pentingnya peranan guru di era revolusi industri keempat (RI 4.0) dan era Masyarakat Ekonomi Asean (MEA) ini sudah seharusnya guur di Indonesia mampu memberikan kontribusi positif dalam hal pembangunan manusia Indonesia. Kontribusi tersebut dapat berupa upaya memperbaiki proses pembelajaran di kelas secara berkelanjutan. Pemanfaatan teknologi informasi dan komunikasi dalam pembelajaran bisa jadi alternative untuk perbaikan tersebut. Untuk mampu mengintegrasikan teknologi informasi dan komunikasi dalam mengajar diperlukan kerangka Technological Pedagogical 
Content Knowledge (TPACK) oleh seorang guru. Oleh karena itu, sudah seharusnya guru di Indonesia memiliki kemampuan tersebut agar bisa mewujudkan tujuan pendidikan nasional sehingga bangsa Indonesia bisa bersaing dengan bangsa lainnya di era RI 4.0 dan era MEA saat ini.

\section{DAFTAR RUJUKAN}

Amin, 2017. Kriteria Calon Guru Masa Depan, (Online), (https:// campus. imcnews.id/read/kriteria-calon-guru-masa-depan). Diakses pada 2 Mei 2018.

Archambault, L. M., \& Barnett. J.H. 2010. Revisiting Technological Pedagogical Content Knowledge: Exploring the TPACK frame work. Computer and Education,(Online).(https://www.sciencedirect.com/science/article/pii/S0360131510002010). Diakses pada 3 Mei 2018.

Arifin, 2017. Kriteria Instrumen Dalam Suatu Penelitian. Vol. 2 No.1, hal 28-36. Program Studi Pendidikan Matematika, Universi-tas Majalengka.

Arikunto, S. 2011. Prosedur Peneliti-an Suatu Pendekatan Praktik. Jakarta: Bumi Aksara.

Arnyana, I.B.P. 2007. Pengembangan Profesionalisme Guru Biologi di Era Global. Jurnal Pendidikan dan Pengajaran UNDIKSHA. Edisi Khusus XXXX:4 72-490.

Azwar, S. 2013. Metode Penelitian. Yogyakarta: Pustaka Pelajar.

Dahar, R.W. \& Siregar, N. 2000. Pe-dagogik Materi Subyek; Meletak-kan Dasar Keilmuan Dari PBM. Jurnal FPMIPA (Online), (jour-nal.fpmipa.upi.edu/index.php/). Diakses pada 27 April 2018.

Fadlan, A. 2010. Strategi Pening-katan Keterampilan CAlon Guru Dalam Menerapkan Pembelaja-ran Aktif melalui MEI (Modelling, Engaging, and Integrative). Jurnal Kependidikan Dasar, Vol.191): 88-96.

Hewitt, J. 2008. Reviewing The Handbook of Technological Pedagogical Content Knowedge (TPCK) for Educators. Journal of Science, Mathematics And technology Education, (Online), 8(4):355360, (http://www.tandfonline.com/doi/abs/10/1080/1231231425353232423?journalCode=ucjs20), diakses 10 Juli 2018.

Hidayat, R. 2015. Pemanfaatan tek-nologi informasi dan komunikasi oleh guru sosiologi dalam menyampaikan materi pembelajaran di kelas, (Online), (https ://www.kompasiana.com/ rian-hidayat/pemanfaatan-teknologi-informasi-dankomunikasi-oleh-guru-sosiologi-dalam-menyampa-ikan-materi-pembelajaran-di-ke-las), diakses pada 29 April 2018.

Iftitah, K. N. 2017. Profil Tech-nological Pedagogical Content Knowledge (TPACK) guru IPA pada jenjang sekolah menengah kejuruan (SMK). Malang: Univer-sitas Negeri Malang.

Irina, A., \& Liliana. 2011. Pedagogi-cal Campetence, the key to efficient education, Internasional Online Jurnal of educational Science. Diakses pada 27 April 2018.

Jordan, K. 2011. Beginning Teacher Knowledge: Result from Self-Assessed TPACK Survey. Austra-lian Educational Computing. 26 (1): 16-26.

Koehler, M. J., \& Mishra, P. 2008. Introducing TPCK In AACTE Committee on Innovation \& technology (Eds.), Handbook of technological pedagogical con-tent knowledge for education (pp. 3-29) New York, NY: Routledge.

Koehler, M.J., Mishre, P., Akcaoglu, M., \& Rosenberg, J.M. 2013. The Technological Pedagogical Content Knowledge Framework for Teachers and Teacher Educators. ICT Integrated Teacher Education: A FResource Book,(Online),(http://www.cemca.org.in/ckfinder/userfiles/files/ICT\%20teacher\%20education\%20Module\%201\%20Fin al_May\%2020. pdf). Diakses pada 25 April 2018.

Lestari, D. 2015. Analisis Kemam-puan Technological Pedagogical, Content Knowledge (TPACK) Pada Guru SMK. Jurnal Pendidikan. (Online). (http:/digi-lib.its.ac.id/ITS-paper-61234221-131205804/33403). Diakses pada 11 Juli 2018.

Mar'atus, S., Yuliati, L., Wartono. 2016. Peranan TPACK Terhadap Kemampuan Menyusun Perang-kat Pembelajaran Calon Guru Fisika Dalam Pembelajaran Post-Pack.. Jurnal Pendidikan. (On-line).(http://www.jstor.org/about/ITSpaper61234221131205804/3-3403). Diakses pada 8 Juli 2018.

Mishra, P., \& Koehler, M.J. 2006. Technological Pedagogical Content Knowledge: A New Framework for teacher kno-wledge. Teacher Cellege record.(Online), (https://www.researchgate.net/publication/220041541 Technological Pedagogical Content Knowledge A Framework for Teacher Knowledge). Diakses pada 25 Mei 2018.

Notoarmodjo, S. 2003. Pendidikan Dan Perilaku Kesehatan. Jakarta: Rineka Cipta.

Peng, W. 2013. Examining Pedagogical Content Knowledge (PCK) for Business English Teaching: Concept and Model. Polyglassia.25: 83-94. (online) http://digilib.unimed.ac.id/UNIMED-Article-30983-Pedagogik_UMN.pdf. Diakses pada 16 Mei 2018.

Purwanto, 2013. Evaluasi Hasil Belajar. Celeban Timur UH III Yogyakarta 55167: Pustaka Belajar.

Purwianingsih, W. 2011. Pengem-bangan Program Pembekalan Pedagogical Content Knowledge (PCK) Bioteknologi Melalui Perkuliahan Kapita Selekta Biologi. Tesis. Universitas Pen-didikan Indonesia, Bandung. http://repository.upi.edu/7553/. Diakses tanggal 26 Mei 2018. 
Puspitarini, Erri. W., Sunaryo, S., E. 2013. Pemodelan Technological Pedagogical Content Knowldege (TPACK) Berbasis Teknologi Informasi Dan Komunikasi (TIK) Dengan Pendekatan Struktur Equation Modeling (SEM). Jurnal Pendidikan. (Online). (http:/digilib.its.ac .id/ITS-paper-910221140005804/33403). Diak-ses pada 10 Juli 2018.

Ratnadewi. 2013. Kriteria Guru Profesional: Peningkatan Profesi-onalisme Guru, (Online). (https:// ratnadewi87.wordpress.com/tag/kriteria-guru-profesional/). Diakses pada 29 April 2018.

Riduwan. 2014. Dasar-dasar Statis-tika. Bandung: Alfabeta.

Rusman. 2012. Model-Model Pembe-lajaran. Bangdung: Seri mana-jemen Sekolah bermutu.

Rosyada, D. 2016. Kompetensi Pedagogik Guru, (Online), (http:// www.uinjkt.ac.id/id/kompetensi-pedagogik-guru/) diakses pada 29 April 2018.

Rosyid, A. 2015. Technological Pe-dagogical Content Knowledge: Sebuah Kerangka Pengetahuan Bagi Guru Indonesia Di Era MEA. Jurnal Fakultas Ilmu Pendidikan UNS, (Online). (jurnal.fkip.uns.ac.id/index .php/snip/article/viewFile/8962/6523). Diakses pada 27 April 2018.

Sahin, I. 2015. Devolopment of Survey of technological Peda-gogical Content Knowledge (TPACK). The Turkey Jurnal of education technology. (Online). Diakses pada 15 Juni 2018.

Sahin, I. 2013. Analysis of Relationships Between Tech-nological Pedagogical Content Knowledge and Educational Internet Use. Journal of Digital Learning in Teacher Education, 29(4): 110-117

Setyawan, A. 2013. Metedologi Penelitian. Surakarta: Politeknik Kesehatan.

Schmidt, D. A., E. Baran, A. D. Thompson, P. Mishra, M. J. Koehler, dan T. S. Shin. 2009. Technological Pedagogical Content Knowledge (TPACK): The Development and Validation of an Assessment Instrument for Preservice Teachers. Journal of Research on Technology in Education. 42 (2): 123-149.

Slavin, R. E. 2009. Education Psychology: Theory and Praktice. New Jersey: Pearson Education, Inc.

Smaldino, E. 2011. Teknologi Pembe-lajaran dan Media untuk Belajar, diterjemahkan oleh arif rahman dari Istrukturional Technology And Media For Learning. Jakarta: Kencana Prenada Media Grup.

Sugiyono. 2009. metode Penelitian Bisnis (Pendekatan Kuantitatif, kualitatid dan R \& D). Bandung: Alfabeta.

Sugiyono. 2011. Metode Penelitian Pendidikan: Pendekatan Kuanti-tatif, Kualitatif, dan R\&D. Ban-dung: Alfabeta.

Shulman. 1986. Those Who Under-stand: Knowledge Growth in Teaching. Education Research. Vol.15(2): 4-14.

UM. 2017. Pedoman Penulisan Karya Ilmiah (Edisi Keenam). Malang: Universitas Negeri Ma-lang.

Undang - Undang Republik Indon-esia No. 14 tahun 2005 tentang Guru dan Dosen. Direktorat Jendral Kelembagaan IPTEK dan DIKTI Kementrian Riset, Tekn0-logi, dan Pendidikan Tinggi, (Online). (http://kelembagaan.ris-tekdikti.go.id/). Diakses pada 